\title{
Development through Gender Equity and Women Empowerment
}

\author{
Dr (Mrs.) Stella Ngoz Induka-Ozo ${ }^{1}$, Dr. Igba Daniel Igba ${ }^{2}$ \\ ${ }^{1}$ Department of Educational Foundations, Ebonyi State University, Abakaliki. \\ ${ }^{2}$ Department of Arts and Social Science Education, Ebonyi State University, Abakaliki.
}

\begin{abstract}
Gender has been conceptualized from different perspectives, but whether in social or cultural terms, the evil connotation tends towards gender inequity or inequality which culminate in gender discrepancy and discrimination. The cultural values of Nigeria place women in the home passively subordinate to men in every sphere of life. The inferior status of the women cautions and sensitizes them to the possible consequences of violating social norms. Women in Nigeria have indeed been denied equal rights to basic education, economic advancement, always alienated in matters of governance through discriminatory and often times harmful traditional practices that have deliberately humiliated them. Women tend to be more sensitive to issues of affiliation, inclusion, loneliness and acceptance. They have greater tenderness, understanding and better control of emotions, which is why there can be no effective development strategy hi which women should not play a central role. Development is a process of change to a better, more advanced and highly organized conditions (Osim 2007). No full development can be attained without utilizing the potentials of the women population that constitute the substantial fraction of the total population, but women must close ranks for the total liberation and empowerment of women so that they can contribute their quota to our national development.
\end{abstract}

Keywords-Development, Gender, equity, empowerment, development.

\section{INTRODUCTION}

Uzoezie (2007) observed that gender is the role or characteristics the society gives to people. These roles are socially determined as distinct from those that are biologically determined (sex) and therefore learned through the socialization processes. They vary between culture and people, and may change over time. Gender is a relational term and not simply 'womaness' or 'manness', just like the concepts of ethnicity, race and class; and can be used as an analytical tool for understanding social processes. Gender may also be defined as the economic, socio-political and cultural attributes and opportunities associated with being male a.id female, which are not fixed but are ascribed, taught and learned through the socialization process. In extreme cases, gender may become 'stereotyped', leading to inferiority complex. To overcome such complex, the advocates of gender mainstreaming seek to highlight the central ity of gender concerns and women's empowerment to development goals, hence they advocate for gender equity and equality.

\section{Gender equity}

Gender equity is seen as the process of being fair to women and men. To ensure fairness, measures must often be available to compensate for historical and social disadvantages that prevent women and men from otherwise operation on a level playing field (Achike 2006). For instance, at the early recruitment stage there is high rate of women turnover and high performance in the work place. At the middle career stage, however, as a result of societal adjustments, workplace pressure and stress from home, there is a noticeable change of attitude to work. This change of attitude to work demands that something should be done since there are talented and capable women whose neglect or out-right exclusion from decision making levels might constitute losses in human capital development. Equity maintains Achike (2006) leads to equality.

\section{Gender equality}

Hannan (2008) posits that gender equality refers to the equal rights, responsibilities and opportunities or women and men, girls and boys. Equality is not a 'woman's issue' but should concern and engage men as well as women. Equality does not mean that men and women should become the same, but that women's and men's rights, responsibilities and opportunities will not depend on whether they are born male or female. They should enjoy the same status, with equal conditions for realizing their full human rights and potential to contribute to national, political, economic, social and cultural development, and to benefit from the results. The above explanations, however, do not amount to giving same treatment to expect same 
result; rather the same result could be expected with different treatment geared towards creating the same level playing field. Gender equality is, therefore, the equal valuing by society of both the similarities and differences between women and men, and the varying roles that they play. The bane of gender inequity or inequality is gender discriminationor gender discrepancy.

\section{Gender discrepancy}

Simply put, is lopsidedness in the mix of male and female. It is a skew towards males or females which create an imbalance; it is a tilt, particularly against the female or girlchild population.

Evidence of gender imbalance: Contributing on gender and politics Haruna (2007) asserted that it is a known fact that unequal power relations exist between men and women in the area of decision making, access to and control over resources and so on. A situation where men are the commissioners and permanent secretaries for the ministries of women affairs leaves much to be desired. The plight of women has attracted global concern; and various bodies have taken keen interest to see that this imbalance is redressed. The UnitedNations Charter (1945) made provision for fundamental human rights - the dignity and worth or value of the human person and equal rights of men and women of all nations. The United Nations Organization (UNO) have, through conferences, articulated the problems and prospects of women in development. These conferences included that of Mexico in 1974, Copenhagen in 1980, Nairobi in 1985 and Beijing in 1995. Among other things, these conferences evolved strategies on liberation of women from societal conservatism and recommended the establishment of Women Development Centres, which will largely sensitize women on their self-actualization and generally enhance their integration into the socio-political development of the society as equal participants and beneficiaries. In sponsoring a bill on violence against women, Aya (2002) noted that some aspects of our culture encourage violence against womdn and need to be prohibited. To be eradicated also are all forms of discrimination against women; for full enjoyment of the fundamental rights of women as entrenched in the Constitution of the Federal Republic of Nigeria.

\section{Women empowerment}

Women have been called all sorts of names including the 'weaker sex'. Weaker sex indeed! A women wakes up at 5 o'clock in the morning with a baby strapped on her back and begins to clean-up the house, prepare the breakfast, and get the older children ready for school before preparing for work herself. Meanwhile the husband is fast asleep, only to get up at 7 o'clock and demand for hot water to bathe before proceeding to the table for his meal, and off he goes to work. In the rural of Nigeria, a mother with a bundle of firewood on her head and a child strapped on her back is a common sight. In Germany over 70 percent of mothers feel stressed. About 51 percent have complaints involving the spine and intervertebral disks; over a third is constantly tired and despondent, while 30 percent suffer from headaches or migraines (Awake 2002).

Akanu (2007) gave a pathetic illustration of the work load on women in Nigeria (See fig I). The task connected with the home are the fundamental tasks of humanity, if a mother does not do her duty, there will be no next generation, or a next generation that is worse than none at all. With even a limited education, a mother can make a difference. The saying is true that when you educate women, you educate the teachers of men. Women tend to be more sensitive to issues of affiliation, inclusion, loneliness and acceptance. They have greater tenderness, understanding and better control of emotions. Their role in the survival and continuity of any society is certainly not under contentions. What has remained an issue of serious concern is that inspite of the acknowledged role women play in nation building and development, various societies have continued to treat them as second class citizens. Women are hardworking, dependable, obedient and when given the chance are accountable in handling positions of trust. 


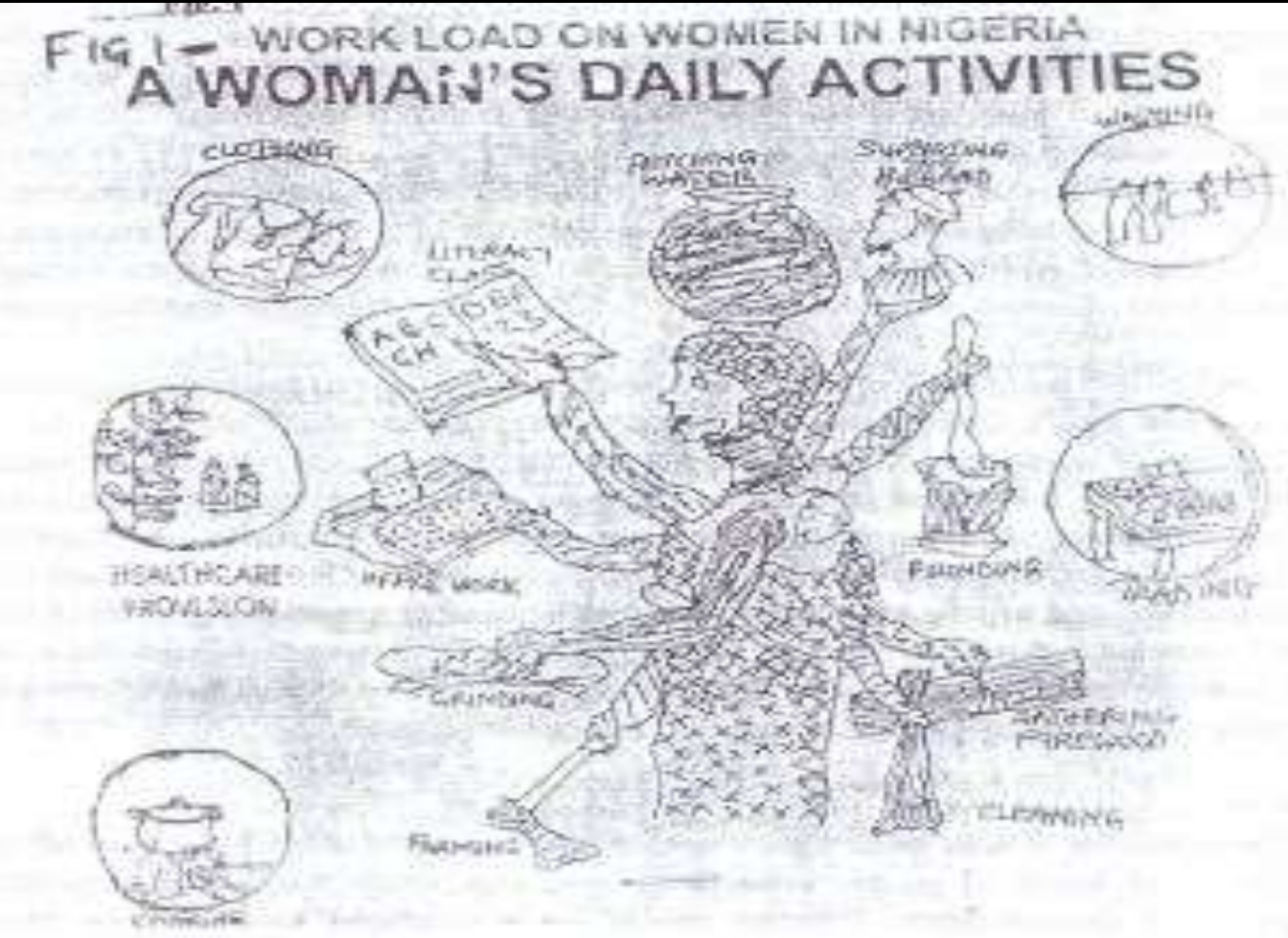

Fig.1: Work Load on Women in Nigeria

The truth of the matter is that before the 90's in Nigeria the girl child had lower schooling opportunity. During the buoyant economic era however, Nigeria recorded significant increase in female graduates compared to their male counterparts. However, female education as Fafunwa (1974) puts it is generally skewed towards subjects considered to be of least resistance, higher compeitition and in lower demand, excluding them from their interests abilities and capabilities which are the three indices of career choice (Nduka-Ozo, 2009).

\section{Women empowerment and development}

"Study after study has shown that there is no effective development strategy in which women do not play a central role. When women are fully involved, the benefits can be seen immediately: familieis are healthier and better fed; their income, savings and reinvestment group; and what is true of families is also true of communities and, in the long run, or whole countries" (Annan, 2003).

Egwu (2007) observed that countries all over the world have been acknowledging the logic that no full development can be attained without utilizing the potentials of the women population that constitute the substantial fraction of the total population. This truth underscored the Federal Government's promulgation of Decree no. I I of 1995 establishing the National Centre for Women Development in 1992 in Abuja. Continuing he lamented that women in the past, despite their noble roles in the development of the society, have not been well treated. They have indeed been denied equal rights to basic education, economic advancement, always alienated in matters of governance through discriminatory and often times harmful traditional practices that have deliberately humiliated them.

Development is a process of change to a better, more advanced and highly organized conditions (Osim 2007). Development is not only the provision of infrastructure, but a gradual process of advancement which include mental, physical, economical and social condition of a people. It is on this premise that students are given scholarship, workers are given in-service training; other forms of support are given in other to empower individuals for their development and advancement Women need such support. Development itself is a continues process, and as long as women exist, their contributions to the growth of the nation will continue if given the required encouragement. They have been involved in all facets of development inspite of the apparent neglect, lack of appreciation of their efforts and inhibitions by cultural and religious beliefs. 


\section{CONCLUSION}

The potentials of women to a great extent have remained unutilized as a result of subjugation by all forms of gender inequity or inequality which culminates in gender discrepancy and discrimination. Women should be encouraged to overcome their deprivations and disabilities; they need to be empowered socially, politically, educationally and economically to enhance their full emergence into the main stream of national and international socio-political development. Efforts to empower women may be unrealistic if they wallow in ignorance; education is the passport to women liberation, total emancipation and consequent empowerment for proper advancement. The fewwomen that have been tried and tested have all delivered, women like Margaret Thatcher, the 'iron lady of Britain, Emelda Marcos of Philippines, Prof Dora Akunyili of Nigeria, etc. I, therefore, call on women to close rank and make use of your numerical strength to attain higher positions in politics, in business and other fields of human endeavor. No effort should be spared in the total liberation and empowerment of women so that they can contribute their quota to our national development. Egwu (2005) opined that International Women's Day Celebration should transcend the romanticisation of the female gender to the celebration of women as strategic vehicles for the socio-economic and political development of the society.

\section{Implication}

The implication of encouraging women to overcome their deprivations and disabilities will not only enhance their full emergence into the main stream of the affairs of the nation through tapping their natural endowment talents, abilities and capabilities but will, on the long run, lead to the realization of their potentials and goals; hence their selfactualization. The outcome of an enabling and facilitative environment can never be over-emphasized; people put in their best when they are encouraged. Again, women education should be encouraged as it has been noted above that efforts to empower women may be unrealistic if they wallow in ignorance; education is a sure way for women liberation and ultimate emergence of well-groomed families that should metamorphose into awell groomed nation.

\section{REFERENCES}

[1] Achike, I. (2006). Theoretical and Analytical Framework for Gender Analysis of Public-Sector Budgets. A Paper presented at the UNDP supported workshop at Grace Court Hotel and Suites, Abakaliki.
[2] Akanu, C.C. (2007). Role of Women. In Women Development Platform. Abakaliki: Women Development Centre.

[3] Anambra State Ministry of Women Affairs and Social Development. (2007). Gender Mainstreaming as a Tool for Sustainable Grass root Development. Nimo: Rex Charles and Patrick Ltd. (I ${ }^{\text {st }}$ Edition)

[4] Annan, K. (2003). The Role of Mothers as Educators. In Awake. New York; Watchtower Bible and Tract Society.

[5] Awake, (2002). Motherhood in Various Lands. New York: Watchtower Bible and Tract Society.

[6] Aya, F. (2002). A Bill on Violence Against Women (Prevention, Protection \& Prohibition) Act 2002. Abuja: The Legislative Advocacy Coalition on Violence against Women (LACVAW)

[7] Egwu, S.O. (2005). A Challenge to my Generation: Selected Speeches. Enugu. Fegno Printing\& Packaging Company Ltd.

[8] Fafunwa, B.A. (1974). History of Education in Nigeria. London: George Allen And Unwin.

[9] Hannan, C. (2008). From Concepts to Action: Gender Mainstreaming in Operational Activities. Paper presented at the UNDP supported workshop at Grace Court Hotel and Suites, Abakaliki.

[10] Haruna, I.I. (2007). Gender, Politics and the Law. In Women Development Platform. Abakaliki: Women Development Centre. 